\section{(2) OPEN ACCESS}

\title{
Developing a shared decision support framework for aortic root surgery in Marfan syndrome
}

\author{
Tom Treasure, ${ }_{1}$ Annette King, ${ }^{2}$ Loreto Hidalgo Lemp, ${ }^{3}$ Tal Golesworthy, ${ }^{4}$ John Pepper, ${ }^{5}$ \\ Johanna JM Takkenberg ${ }^{6}$
}

- Additional material is published online only. To view please visit the journal online (http://dx.doi.org/10.1136/ heartjnl-2017-311598).

${ }^{1}$ Operational Research Unit, Department of Mathematics, University College London, London, UK

${ }^{2}$ Centre for Health Services Studies, University of Kent, Canterbury, Kent, UK ${ }^{3}$ Health Psychology, KCL, London, UK

${ }^{4}$ Exstent Ltd, Cheltenham, UK ${ }^{5} \mathrm{NIHR}$ Cardiovascular Biomedical Research Unit, Royal Brompton Hospital, London, UK ${ }^{6}$ Department of Cardio-Thoracic Surgery, Erasmus University Medical Center, Rotterdam, The Netherlands

\section{Correspondence to}

Professor Tom Treasure, Department of Mathematics, University College London, London, WC1H OBT, UK; tom. treasure@gmail.com

Received 4 May 2017 Revised 28 June 2017 Accepted 28 June 2017 Published Online First 3 August 2017

\section{Linked}

- http://dx.doi.org/10.1136/ heartjnl-2017-312081

Check for updates

To cite: Treasure $T$, King $A$, Hidalgo Lemp L, et al. Heart 2018;104:480-486.

\section{ABSTRACT}

Objective The study is an early phase of development of a decision support framework for people with Marfan syndrome who are anticipating prophylactic aortic root surgery. Implications of the timing and the nature of the operation chosen were previously elicited in focus groups. In this step, we explored the range of relative values placed by individuals on the implications of decisions made about surgery.

Methods Following the principles of the Ottawa Decision Support Framework, eight questions in the general form 'How important is it to you ...' were framed by a panel. Marfan people, families and specialist doctors answered online. Quantitative and qualitative analyses were performed.

Results Worldwide, 142 responses were received including 25 specialist doctors. Respondents were 55\% female and $46 \%$ had previous aortic root surgery. Overall, active lifestyle was more important to males $(p=0.03)$. Patients placed more importance than doctors on not deferring surgery $(p=0.04)$ and on avoidance of anticoagulation in the interests of childbearing $(p=0.009)$. Qualitative analysis showed differing but cogently reasoned values that were sometimes polarised, and mainly driven by the wish to maintain a good quality of life and active lifestyle.

Conclusions Given the cogency of these viewpoints, people anticipating root replacement surgery should have ample opportunity to express them and to have them acknowledged ahead of a consultation when they can then be fully explored in a mutually informed forum. If they differ from local medical practice, they can then be discussed in the process of reaching shared and individualised decisions.

\section{INTRODUCTION}

Prophylactic surgery to prevent dissection in congenitally determined aortic root aneurysms is well established. Clinical decision making in this context is related to both the timing of the surgery and the surgical approach. ${ }^{12}$ The timing of surgery depends predominately on the size of the aorta and its growth rate; for many patients, the possibility of dissection of their enlarged aorta may negatively affect their quality of life. The surgical approach that is chosen to prevent dissection may also affect patient quality of life and is value sensitive. The more durable mechanical replacement includes thromboembolic hazard plus the risk of iatrogenic bleeding. The avoidance of those risks with valve sparing surgery carries a substantial life-time risk of valve failure, consequential loss of well-being and a possibility of further surgery. It is a source of considerable debate in recent years. ${ }^{3-14}$ Some patients may prefer a durable solution and accept the burden of anticoagulation when mechanical replacement is chosen, while others may prefer the less durable approach of valve sparing surgery to avoid anticoagulation.

Given the complexity and the value-sensitive nature of the decisions that are required in this setting, there is a need for an evidence-based decision support framework to optimise the decision-making process. The Ottawa Decision Support Framework (ODSF) offers an evidence-based, practical, midrange theory for guiding patients making health or social decisions. ${ }^{15-17}$ The ODSF uses a three-step process:

1. to assess client and practitioner determinants of decisions to identify decision support needs

2. to provide decision support tailored to client needs (counselling, decision tools such as patient decision aids and decision coaching)

3. to evaluate the decision-making process and outcomes.

A recent randomised trial in patients requiring heart valve replacement showed that although the use of a decision aid that was built using the ODSF to support prosthetic valve selection did not result in less decisional conflict, it did result in better patient knowledge of heart valve prostheses, patients feeling better informed, less anxious and depressed and a better mental quality of life at the time of the decision making. ${ }^{18}$

Focus groups have previously indicated that patients with Marfan syndrome and related disorders want to understand the alternatives they have in the complex decision making they are facing and voice their preferences. ${ }^{19}$ The purpose of this study is to explore what are patient and physician preferences for timing of an intervention and the consequences of choosing valve sparing or valve replacing strategies, as a starting point for developing an ODSF decision support instrument that could be used to set the context of conversations with patients with the purpose of making shared decisions.

\section{METHODS}

Already identified in focus groups were the themes that most concerned people who had had aortic root surgery. ${ }^{19}$ These included the timing of surgery, leading an active lifestyle, commitment to 


\begin{tabular}{ll}
\hline Table 1 & The eight questions \\
\hline 1 & How important is it to you to postpone having an operation on your aorta for as long as the doctors think it is safe to do so? \\
2 & How important is it to you to avoid taking anticoagulant (blood thinning) medication? \\
3 & How important is it to you, if you need to have an operation on your aorta, to get on with it and have it behind you? \\
4 & How important is it to you to avoid lifelong medication such as beta blockers or losartan? \\
6 & How important is it to you to avoid repeated visits to the hospital for tests? \\
\hline 8 & How important is to you to have a physically active lifestyle? \\
\hline
\end{tabular}

For the purposes of the study, these questions were set out as a web form (see online supplementary file 1). In clinical practice, this could be presented to the patient (paper or electronic) to take home with sufficient time and space to write in their reflections. It would then be a document for discussion, representing a personal profile of the values brought to the consultation, based on whatever prior knowledge, experience or assumptions the patient might have. For the format of the questionnaire see the web supplement.

anticoagulation, preferences with respect to taking medicines and attending hospital for monitoring. There were specific concerns that would create an impediment to one or other operation for some people, such as the wish for a pregnancy or the avoidance of heart valve noise.

Questions were framed in the style of the $\operatorname{ODSF}^{16} 17$ and were developed by a panel including people with experience of Marfan syndrome, related pathology and surgery including an analyst and comentator ${ }^{20}$ (see Acknowledgements for details) with a range of expertise, knowledge and first-hand experience of Marfan syndrome and aortic root surgery (table 1). Eight questions were presented with a 1-10 Likert scale, each accompanied by a free text box inviting patients to write down any thoughts prompted by the question. (Web extra: questionnaire-including respondent's weighting and free text entry boxes.)

We were advised by the British Integrated Research Application System ${ }^{\mathrm{i}}$ that formal application was not required for this study, which was to be circulated by the Marfan Association (UK) to its members. People with Marfan syndrome, their families and specialist doctors were invited to view the survey via a web link and to participate only if they wished to do so and to send on the link to any of their own contacts. The respondent had to actively open the electronic form, could leave it at any time, and it was only saved with their final confirmation. They were asked to indicate which of five categories they fitted:

1. I may require an aortic root operation at some point in the future.

2. An aortic root operation is actively being considered for me.

3. I have had an aortic root operation.

4. This decision affects a member of my family.

5. I am a medical practitioner.

They were allowed to tick as many as applied, asked to indicate their age and gender, and to add further comments.

There were three planned comparative analyses: male versus female; patients and families versus doctors; and patients anticipating root surgery versus patients who had already undergone root surgery.

\section{Statistical analysis}

Continuous variables were displayed as median, IQR and range. Discrete variables were displayed as counts or proportions. IBM

${ }^{\mathrm{i}}$ Integrated Research Application System: https://www.myresearchproject.org.uk/
SPSS Statistics V.21 was used for all statistical analyses. Comparison between continuous variables was by Student's t-test. Comparison of group responses to the questionnaire was by independent samples Mann-Whitney U test.

\section{The free text answers were analysed using two steps}

First, free text answers were thematically coded to explore the range of experiences and perspectives of the preferences and choices in the study, using the 'Framework' approach ${ }^{21}$ through the NVivo qualitative analysis programme. The analysis involves six key stages: familiarisation, identifying, a thematic framework, indexing, charting, mapping and interpretation. 'Framework' allows combining and exploring predetermined topics (given through the questions) with more open and emerging themes in the free text answers. In a second step, the resulting themes were then further explored by mapping them against the main outcomes of the study results with a view to contextualising numerical responses to the questions.

\section{RESULTS}

\section{Quantitative analysis}

There were 142 respondents. The geographical distribution is shown in table 2 . Of the 142 respondents, there were 10 respondents who selected two categories and two who selected three categories. Age and sex distributions by category are shown in table 3. The age distributions included all patients who had indicated that particular category.

Of the total 119 people with Marfan syndrome (including two doctors), there were 58 males and 61 females. The women responding were (significantly) younger than the men (mean 45 (SD:14) versus 52 years (SD:15). There was no

\begin{tabular}{lc} 
Table 2 Geographical distribution of respondents & \\
\hline Location & Number \\
\hline North America & 26 \\
Western Europe & 84 \\
Central Europe & 13 \\
Eastern Europe & 8 \\
Australasia & 11 \\
Total & 142
\end{tabular}

Respondents were not asked personal details that might identify them, and we did not ask where they lived. From the web strategy to avoid repetitive answering, we had the grid references of the computer used and from that were able to visualised the geographical distribution shown in online supplementary file 2. This table is therefore an approximation because we did not obtain or attempt to work out the exact location of the respondent. 
Table 3 Respondent characteristics ( $n=142)$

$\mathrm{n}=142$ individuals

\begin{tabular}{ll}
\hline Age years median (IQR) (range) & $52(30-65)(12-74)^{*}$ \\
\hline Gender ( $\mathrm{n}(\%))$ & \\
\hline Female & $64(54.9)$ \\
Male & $78(45.1)$ \\
\hline Respondent typet & $\mathrm{N}$ and \% of 156 responses \\
1. May require a future aortic root operation & $40(28.2)$ \\
2. Active consideration of aortic root operation & $5(3.5)$ \\
3. Had an aortic root operation & $65(45.8)$ \\
4. Decision affects a member of my family & $21(14.8)$ \\
5. Medical practitioner & $25(17.6)$ \\
\hline
\end{tabular}

*Three respondents did not provide their date of birth.

TTwelve individuals entered more than one category: $(1,2,4) \times 2 ;(1,2) \times 1 ;(1,4) \times 2$; $(1,5) \times 1 ;(3,4) \times 5 ;(3,5) \times 1$. The duplicate and triplicate ages were retained in each group for analysis of the age distributions.

significant correlation between age and the distribution of the study responses (Pearson's correlation coefficient).

Of 32 bar charts, the eight comparing the responses of males and female (figure 1) and the eight comparing medical and non-medical responses (figure 2) have been presented in the main paper. The full set is in an online supplementary file 3 . There was a strong degree of importance attached to maintaining an active lifestyle by all groups. Men and women put similar importance on avoiding anticoagulation in the interests of pregnancy (figure 1). Patients weighted the importance of getting aortic surgery behind them rather more highly than did their doctors (figure 2).

\section{QUALITATIVE ANALYSIS}

Recurring themes (table 4) were identified as

- maintaining as normal a life as possible,

- preserving a good quality of life in living with Marfan syndrome and

- retaining an active and participatory lifestyle.

In relation to the three dominant themes identified, maintaining an active lifestyle was the one highlighted by doctors as a decisive factor. It may be that the value placed on remaining active, especially physically active, is most accessible to the outside view. Preserving a normal life for as long as possible was also invoked in the decision to delay aortic root surgery.

Commentary in favour of delay included considerations of risks of the procedure and outcome, recovery from the operation, current (good) health and the current life course status, such as having a young family and existing work/study commitments.

Respondents in favour of having the procedure sooner rather than later commented on the disruption and levels of anxiety experienced in waiting for the procedure and the uncertainty and the delay posed in moving forward with one's life. The preferences and sometimes strong views offered in the study were tempered by a sense of pragmatism in dealing with some of the treatments that come with the management of Marfan syndrome.

When considering whether to postpone surgery, most of the doctors took the view that surgery should only be conducted
1. How important is it to you to postpone having an operation on your aorta for as long as the doctors think it is safe to do so?

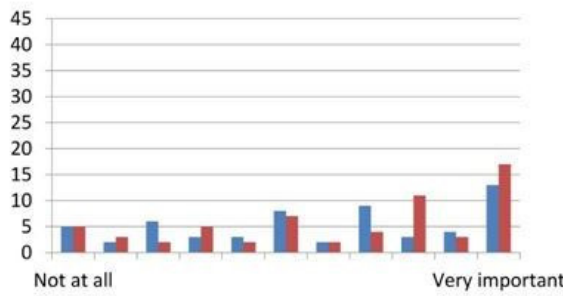

4. How important is it to you to avoid lifelong medication such as beta blockers or losartan?

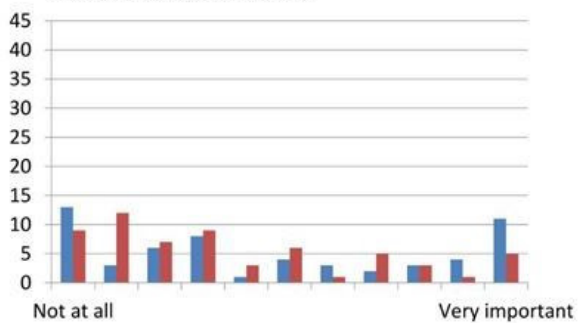

7. How important is it to you to avoid anticoagulation

45 which might be an obstacle to having a baby?

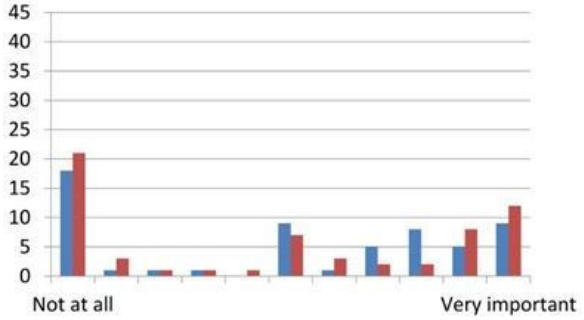

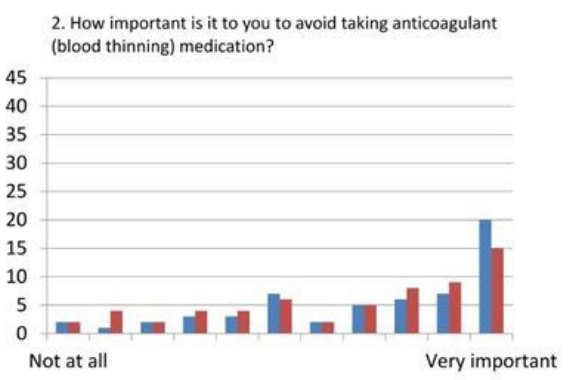
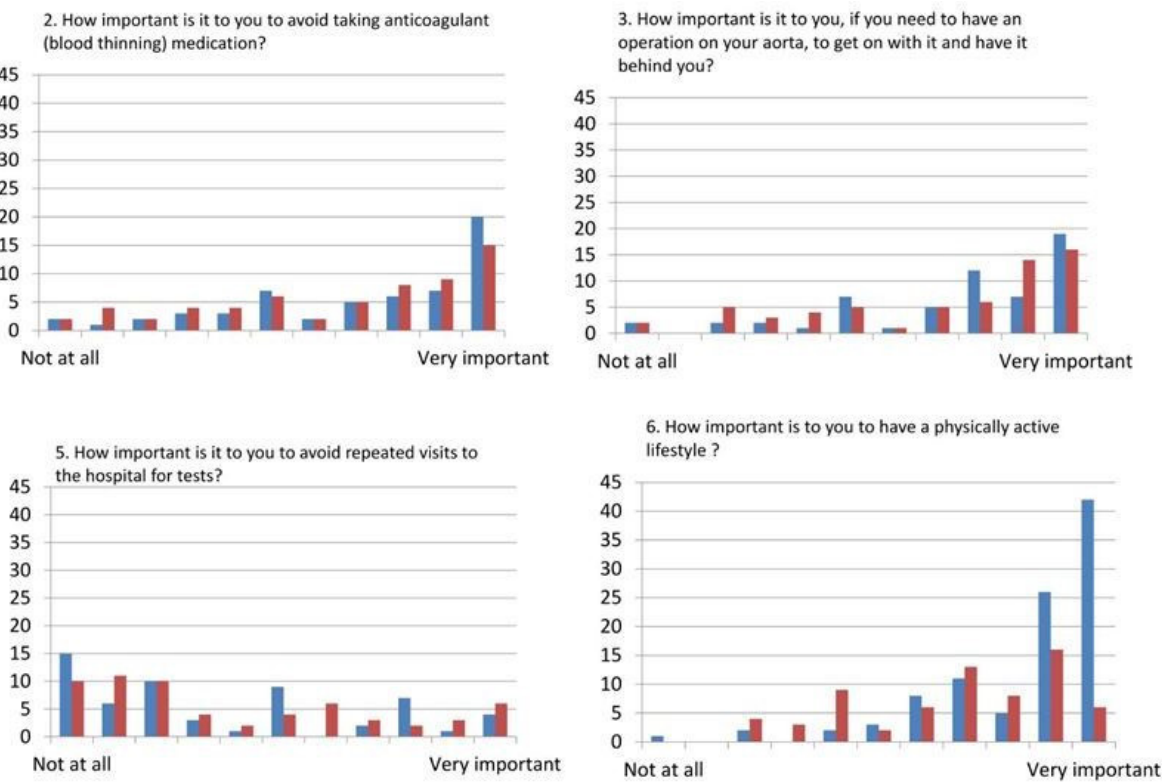

Figure 1 Males ( $n=58$, blue) versus females ( $n=61$, red) of 119 people with Marfan syndrome (including two doctors). 
1. How important is it to you to postpone having an operation on your aorta for as long as the doctors think it is safe to do so?

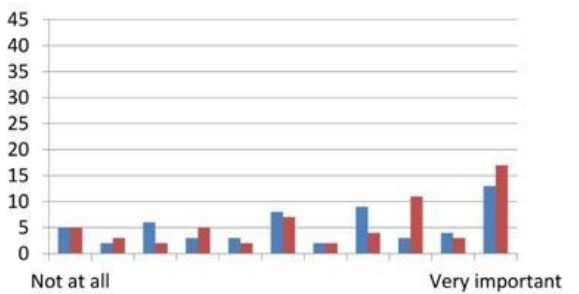

4. How important is it to you to avoid lifelong medication such as beta blockers or losartan?
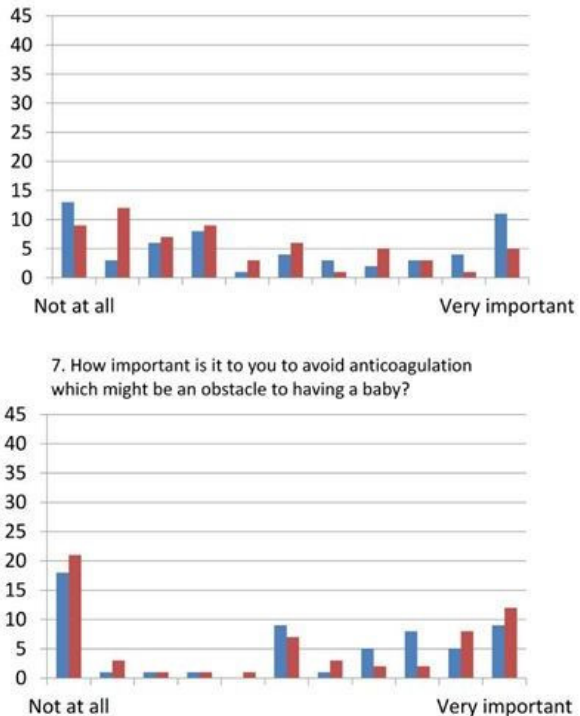
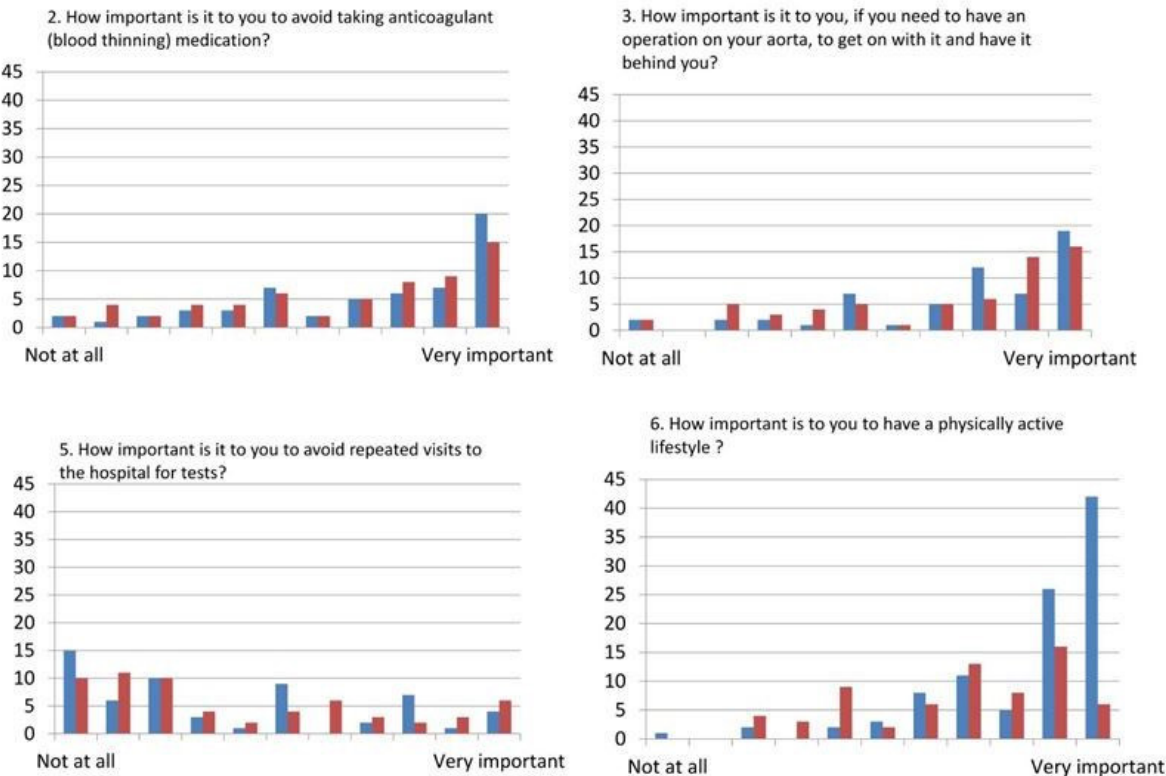

when it became medically necessary because of the risks of the surgery itself, hence taking quite a conservative approach to surgery. The exception to this was the view of one doctor, who made the case for earlier surgical intervention 'Fix the problem may signify return to normal life'.

A fuller qualitative analysis is provided as a supplement.

\section{DISCUSSION}

The purpose of the study is to work towards a decision support framework for patients with genetically determined aortic root aneurysms. The key decisions are what form of operation to have and when to intervene. The two are interdependent: an operation deferred, allowing progression of the aortic root disease, may reduce the prospects of successful valve conservation. Conversely, the preference for valve conserving surgery may bring the operation forward to increase the prospect of success. The choice of surgery between valve sparing and valve replacing root replacement is at present more a matter of discussion than the dimension at which the patient would be advised to have aortic root surgery and so it is considered first in this discussion. ${ }^{6-9} 13$

An active lifestyle was given high importance both by people with Marfan syndrome and their doctors, more so by men than women (figure 1 and 2). This implies avoidance of anticoagulation, which is also an obstacle to straightforward pregnancy. This question (no. 7) elicited a bimodal response and the free text qualitative analysis makes it clear that those less concerned are older and have completed their families. There is no difference between men and women in this regard (figure 1). This is a well-informed patient group; they are often part of families with a lived experience of the condition and its consequences, and they have well-organised patient associations. The high importance placed on an active life style and on pregnancy leads to a preference for valve sparing surgery. Counselling for patients expressing that preference should include consideration of the lifetime probability of valve failure and further intervention.

Patients placed more importance on getting on with an operation than did their doctors (figure 2) who in the free text qualitative analysis explained their preference for postponing surgery was for the avoidance of surgical risk. In this young group of patients, risk is in fact low. Furthermore, there is 'a risk in avoiding risk' if the opportunity is lost to have the more conservative forms of surgery. ${ }^{22}$ Unlike their doctor, who sees them for a short consultation every few months, patients may have a constant awareness the risk of a sudden life-threatening event. Some patients avoid exertion because of a fear of dissection, further impinging on their quality of life.

There was also a divergence between patients and doctors, and among patients themselves, on the question of tolerating medication while being monitored (figure 2). Doctors thought it was of intermediate importance and patients' responses were bipolar. Of note was the readiness of non-medical individuals to use the limits of the range, reflecting strongly held individual preferences. But doctors tended not to use the limits of the scales, taking a more middle ground view for a range of clinical circumstances, but the patient's rating is the one we want to capture. A patient taking beta blockers may accept lack of physical or sexual performance in exchange for a better chance 


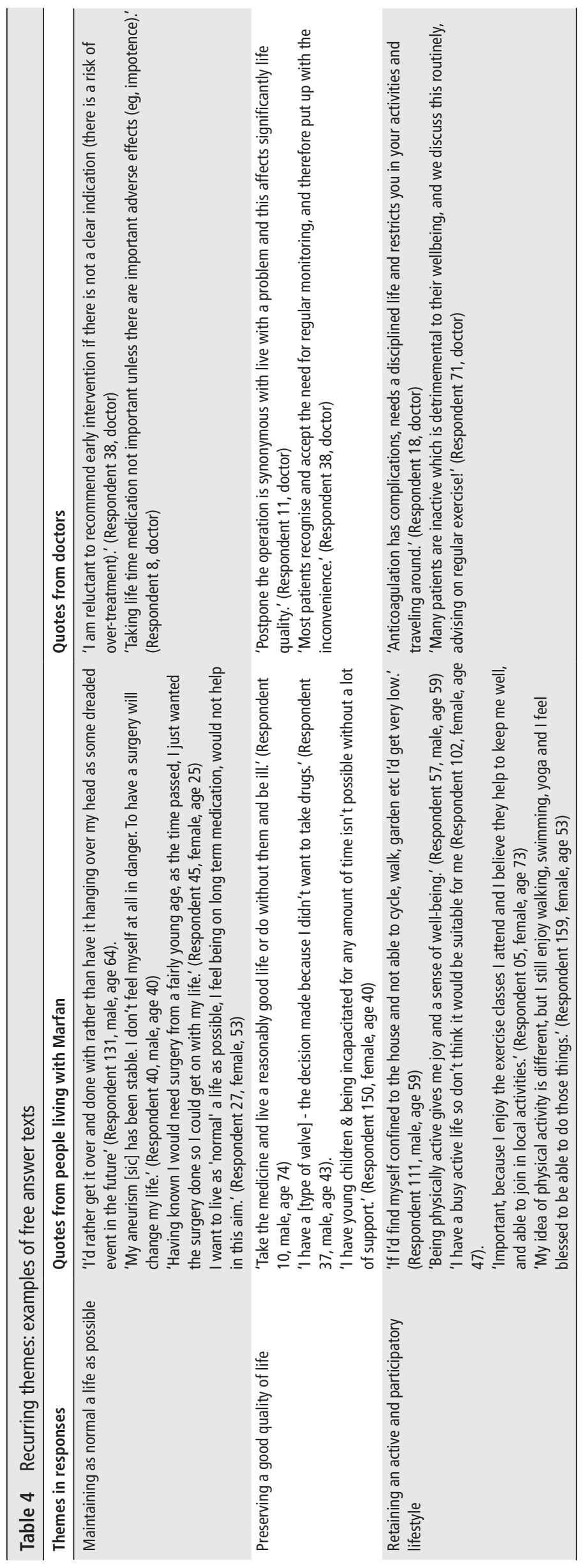


of survival, but have they had adequate opportunity to have the true effect on survival quantified for them $?^{23}{ }^{24}$ Furthermore, might not an expressed intolerance of beta blockers be a sound reason to choose earlier surgery?

Decision aids have been demonstrated to be effective in supporting patients and doctors making shared treatment decisions, particularly in circumstances where there are various treatment options available, but with outcomes that may result in different benefits and harms. ${ }^{25}$ A recent update of a systematic review in decision aids concluded that such tools resulted in better knowledge of options and outcomes by patients and that they were more satisfied with the decision. There is moderate evidence that patients took a more active role in decision making, and authors concluded that there is emerging evidence of directly value-based choices through decision aids and positive effects on communication between patient and health practitioner. ${ }^{1826-28}$

Well-known limitations of 'surveys' are small size and biased sample. The Marfan Foundation in the USA is advised by its Professional Advisory Board who have declined to work with us previously in efforts to inform patients of the full range of options now available to them. The Foundation did not answer our request to have this study shared with their members. This is a concern for us, and it should be remembered if a 'small sample size' limitation of the study is considered particularly for a rare disease. ${ }^{29}$ The UK Marfan Association have been helpful throughout. It should also be remembered that for this sort of exercise, there may be no calculable size to 'power' the study; there is instead a judgement to be made about whether 'saturation' has been reached. It is our view that it is unlikely that substantially important new themes would have emerged with a larger sample size and that there was sufficient recurrence of themes to conclude that theme saturation had been reached. With respect to bias, we believe that the 142 patients were reasonably representative from the age range and distributions but, in any case, we are interested in developing a process for individuals and rather than drawing inferences from the numbers of people giving any particular view. More important is that the full range

\section{Key messages}

What is already known on this subject?

The threshold dimensions and other factors determining the timing of elective surgery for congenitally determined aortic root aneurysms are the subject of well-developed clinical guidelines largely devised and implemented by medical professionals.

\section{What might this study add?}

Using the Ottawa Decision Support Framework, we have explored how patients' preferences for the timing of an intervention and the consequences of choosing valve sparing or valve replacing strategies can be elucidated prior to a decisionmaking consultation.

\section{How might this impact on clinical practice?}

Patients with these conditions are frequently within families who share the condition and belong to patient associations. They have knowledge and experience of the implications of the timing and choice of operation and their satisfaction with care might be optimised if these were more recognised, acknowledged and used in the making of decisions with lifetime consequences for them. and variety of likely views were probably captured. Future work is likely to include a wider use of social media. ${ }^{30}$

\section{CONCLUSIONS}

The use of a decision support framework should not be regarded as replacing face-to-face counselling. Instead it allows patients to weigh up their choices and come to the consultation more prepared for a discussion of the decisions that face them. The next step in this project is to encourage teams counselling people, making these decisions to test this process. We seek collaborators willing to do so and are actively disseminating these findings to patient groups.

Acknowledgements We are grateful to the additional non-author members of the question framing panel (alphabetical): Kathryn Baurley (Britain) has undergone aortic root surgery and has several family members with Marfan syndrome. Graeme Hankey (Australia): neurologist and health service researcher who has had aortic root surgery and written about his experience. ${ }^{20}$ Robert Shreiber (USA): patient and data analyst.

Contributors JJMT, JP, TG and TT saw the need for the study and initiated the project. LHL and JJMT independently suggested the Ottawa Decision Support Framework as a basis for the study. All contributors worked to devise the eight questions with major input from other panel members acknowledges. LHL devised the web-based format and handled the data retrieval. JJMT led on quantitative analysis. AK performed the quantitative analysis. TT made the first draft, which was extensively revised by JJMT and AK. All authors read and commented on the manuscript during its development and agreed its final form.

Competing interests TG is a shareholder and director of Exstent Ltd, which holds the Intellectual Property in the Personalised External Aortic Root Support project. No other authors have a financial interest or have received any research funding or expenses.

\section{Ethics approval IRAS.}

Provenance and peer review Not commissioned; externally peer reviewed.

Open Access This is an Open Access article distributed in accordance with the Creative Commons Attribution Non Commercial (CC BY-NC 4.0) license, which permits others to distribute, remix, adapt, build upon this work non-commercially, and license their derivative works on different terms, provided the original work is properly cited and the use is non-commercial. See: http://creativecommons.org/ licenses/by-nc/4.0/

(c) Article author(s) (or their employer(s) unless otherwise stated in the text of the article) 2018. All rights reserved. No commercial use is permitted unless otherwise expressly granted.

\section{REFERENCES}

1 Vahanian A, Alfieri O, Andreotti F, et al. Guidelines on the management of valvular heart disease (version 2012). Eur Heart J 2012:33:2451-96.

2 Svensson LG, Adams DH, Bonow RO, et al. Aortic valve and ascending aorta guidelines for management and quality measures: executive summary. Ann Thorac Surg 2013;95:1491-505.

3 Coselli JS. It's time to get to the root of things. J Thorac Cardiovasc Surg 2016;151:291-3.

4 Coselli JS. Aortic root replacement, the 'gold' standard: All that shines is not gold!. . Thorac Cardiovasc Surg 2016;152:956-7.

5 Di Marco L, Pacini D, Pantaleo A, et al. Composite valve graft implantation for the treatment of aortic valve and root disease: results in 1045 patients. J Thorac Cardiovasc Surg 2016;152:1041-8.

6 Price J, Magruder JT, Young A, et al. Long-term outcomes of aortic root operations for Marfan syndrome: a comparison of Bentall versus aortic valve-sparing procedures. J Thorac Cardiovasc Surg 2016;151:330-8.

7 Cameron D. External support of the dilated aorta: back to the future? Heart 2014;100:908

8 Coselli JS, Volguina IV, LeMaire SA, Sundt TM, et al. Early and 1-year outcomes of aortic root surgery in patients with marfan syndrome: a prospective, multicenter, comparative study. J Thorac Cardiovasc Surg 2014;147:1758-67.

9 Shrestha M, Baraki H, Maeding I, et al. Long-term results after aortic valve-sparing operation (David I). Eur J Cardiothorac Surg 2012;41:56-61.

10 Benedetto U, Melina G, Takkenberg JJ, et al. Surgical management of aortic root disease in Marfan syndrome: a systematic review and meta-analysis. Heart 2011;97:955-8.

11 David TE. The aortic valve-sparing operation. J Thorac Cardiovasc Surg $2011 ; 141: 613-5$ 
12 Volguina IV, Miller DC, LeMaire SA, Palmero LC, et al. Valve-sparing and valvereplacing techniques for aortic root replacement in patients with marfan syndrome: analysis of early outcome. J Thorac Cardiovasc Surg 2009;137:641-9.

13 Cameron DE, Alejo DE, Patel ND, et al. Aortic root replacement in 372 marfan patients: evolution of operative repair over 30 years. Ann Thorac Surg 2009:87:1344-50.

14 David TE, Armstrong S, Maganti M, et al. Long-term results of aortic valvesparing operations in patients with marfan syndrome. J Thorac Cardiovasc Surg 2009;138:859-64

15 Légaré $\mathrm{F}, \mathrm{O}^{\prime}$ Connor AM, Graham ID, et al. Primary health care professionals' views on barriers and facilitators to the implementation of the Ottawa Decision support framework in practice. Patient Educ Couns 2006;63:380-90.

16 Légaré F, O'Connor AM, Graham ID, et al. Impact of the Ottawa Decision support framework on the agreement and the difference between patients' and physicians' decisional conflict. Med Decis Making 2006;26:373-90.

17 O'Connor A. User Manual - Values (document on the internet). Ottawa Hospital Research Institute. 2016 decisiona idohrica/docs/develop/User_Manuals/UM_ Values\%20pdf (cited 2016 Apr. 12).

18 Korteland NM, Ahmed Y, Koolbergen DR, et al. Does the use of a decision aid improve decision making in Prosthetic Heart Valve selection? A Multicenter Randomized Trial. Circ Cardiovasc Qual Outcomes 2017;10:e003178.

19 Fosbraey J. The psychosocial impact of personalised external aortic root' 'support surgery in Marfan syndrome. 2014 http://www.marfanaorticrootsupport.org/images/ downloads/The_psychosocial_impact_of_personalised_external_aortic_root_ support_surgery_in_Marfan_syndrome.pdf.
20 Hankey GJ. You need an operation. The Lancet 1999;353(Suppl 1):S35-S36.

21 Pope C, Ziebland S, Mays N. Qualitative research in health care. analysing qualitative data. BMJ 2000;320:114-6.

22 Treasure T, Hasan A, Yacoub M. Is there a risk in avoiding risk for younger patients with aortic valve disease? BMJ 2011;342:d2466.

23 Bowen JM, Connolly HM, syndrome Of Marfan's. Mice, and medications. N Engl J Med 2014;371:2127-8.

24 Lacro RV, Dietz HC, Sleeper LA, et al. Atenolol versus losartan in children and young adults with Marfan's syndrome. N Engl J Med 2014;371:2061-71.

25 Joseph-Williams N, Newcombe R, Politi M, et al. Toward Minimum Standards for Certifying Patient Decision Aids: a Modified Delphi Consensus process. Med Decis Making 2014;34:699-710.

26 Stacey D, Legare F, Col NF, et al. Decision aids for people facing health treatment or screening decisions. Cochrane Database Syst Rev 2014;1:CD001431.

27 Korteland NM, Kluin J, Klautz RJ, et al. Cardiologist and cardiac surgeon view on decision-making in prosthetic aortic valve selection: does profession matter? Neth Heart J 2014;22(7-8):336-43.

28 Korteland NM, Bras FJ, van Hout FM, et al. Prosthetic aortic valve selection: current patient experience, preferences and knowledge. Open Heart 2015;2:e000237.

29 Schumacher KR, Stringer KA, Donohue JE, et al. Social media methods for studying rare diseases. Pediatrics 2014;133:e1345-e1353.

30 Gill FJ, Leslie GD, Grech C, et al. Using a web-based survey tool to undertake a Delphi study: application for nurse education research. Nurse Educ Today 2013;33:1322-8. 